\title{
An epidemiological approach for the estimation of disease onset in Central Europe in central and peripheral monogenic retinal dystrophies
}

\author{
Elena Prokofyeva $\cdot$ Robert Wilke • Gunnar Lotz • \\ Eric Troeger • Torsten Strasser • Eberhart Zrenner
}

Published online: 1 April 2009

(C) Springer-Verlag 2009

\section{Erratum to: Graefes Arch Clin Exp Ophthalmol \\ DOI 10.1007/s00417-009-1059-9}

A grant from the European Union was inadvertently left unacknowledged. The corrected Acknowledgements are as follows:

Acknowledgements We would like to thank the team of senior resident ophthalmologists who were in charge of the patients with hereditary retinal degenerations in Tuebingen University Eye Hospital at the time that data collection was conducted: Dr. K. Rüther, Dr. E. Apfelstedt-Sylla, Dr. H. Jaegle and Dr. A. Schuster. Many thanks to Dr. S. Kohl, who helped with genetic data for the patients. This study was supported by the Tistou und Charlotte Kerstan Stiftung Vision 2000 and by EU grant EVI-GENORET LSHG-CT-2005-512036.

The online version of the original article can be found at http://dx.doi. org/10.1007/s00417-009-1059-9.

E. Prokofyeva $(\bowtie) \cdot$ R. Wilke $\cdot$ G. Lotz $\cdot$ E. Troeger $\cdot$ T. Strasser

Bioengineering Medical Laboratory,

Institute for Ophthalmic Research, University of Tuebingen,

Paul-Ehrlich Str. 17,

72076 Tuebingen, Germany

e-mail: elena.prokofyeva@biomed-engineering.de

E. Zrenner

Institute for Ophthalmic Research, University of Tuebingen,

Schleichstr.12-16,

72076 Tuebingen, Germany 